\title{
Dissociating the role of endocannabinoids in the pleasurable and motivational properties of social play behaviour in rats
}

\author{
E.J. Marijke Achterberga, Maaike M.H. van Swieten ${ }^{a}$, Nina V. Driel ${ }^{a}$, Viviana Trezza ${ }^{\text {b }}$, \\ Louk J.M.J. Vanderschuren ${ }^{\mathrm{a}, *}$ \\ a Department of Animals in Science and Society, Division of Behavioural Neuroscience, Faculty of Veterinary Medicine, Utrecht University, Netherlands \\ ${ }^{b}$ Department of Science, Section of Biomedical Sciences and Technologies, University "Roma Tre", Rome, Italy
}

\section{A R T I C L E I N F O}

\section{Article history:}

Received 18 March 2016

Received in revised form 27 April 2016

Accepted 30 April 2016

Available online 3 May 2016

\section{Keywords:}

Social play behaviour

Endocannabinoids

Operant conditioning

Place conditioning

URB597

Rimonabant

Chemical compounds:

URB597 (Pubmed Chem CID: 1383884)

Rimonabant (Pubmed Chem CID: 104849)

\begin{abstract}
A B S T R A C T
Social play behaviour is a vigorous form of social interaction, abundant during the juvenile and adolescent phases of life in many mammalian species, including humans. Social play is highly rewarding and it is important for social and cognitive development. Being a rewarding activity, social play can be dissociated in its pleasurable and motivational components. We have previously shown that endocannabinoids modulate the expression of social play behaviour in rats. In the present study, we investigated whether endocannabinoids modulate the motivational and pleasurable properties of social play behaviour, using operant and place conditioning paradigms, respectively. Treatment with the anandamide hydrolysis inhibitor URB597 did not affect operant responding or social play-induced conditioned place preference (CPP) when administered at a dose $(0.1 \mathrm{mg} / \mathrm{kg})$ known to increase the expression of social play behaviour, while it modestly reduced operant responding at a higher dose $(0.2 \mathrm{mg} / \mathrm{kg}$ ). The cannabinoid-1 (CB1) receptor antagonist rimonabant reduced operant responding when administered at a dose $(1 \mathrm{mg} / \mathrm{kg})$ known to decrease the expression of social play behaviour, although this effect may be secondary to concurrent drug-induced stereotypic behaviours (i.e., grooming and scratching). These data demonstrate that enhancing endocannabinoid levels does not differentially affect the motivational and pleasurable aspects of social play behaviour, whereas $\mathrm{CB} 1$ receptor blockade reduces the motivational aspects of social play behaviour, possibly due to response competition. Thus, endocannabinoids likely drive the expression of social play behaviour as a whole, without differentially affecting its motivational or pleasurable properties.
\end{abstract}

(C) 2016 Elsevier Ltd. All rights reserved.

\section{Introduction}

Social play behaviour is a highly vigorous form of social interaction, in which components of other social behaviours can be discerned, but in an adapted and/or out-of-context manner $[35,39,69]$. Social play is abundantly expressed throughout the juvenile and adolescent periods of life in the majority of mammalian species [35,39,52]. Engaging in social play behaviour is thought to be important for social and cognitive development $[6,40,65]$ as it equips animals and humans with a rich and flexible behavioural repertoire $[53,66]$.

Social play behaviour is highly rewarding [57,67]. Indeed, its expression is modulated through neural systems implicated in other rewards such as food, sex, and drugs of abuse [48,56,69].

\footnotetext{
* Corresponding author.

E-mail address: 1.j.m.j.vanderschuren@uu.nl (L.J.M.J. Vanderschuren).
}

It is generally thought that reward processes consist of different components: pleasure ('hedonics'), incentive motivation, and learning processes, that are mediated via different neural systems [9]. For example, opioids and endocannabinoids are thought to primarily influence the pleasurable properties of a reward, whereas dopamine is considered to be mainly involved in its motivational aspects [7-9,17,19,26,29,43,50].

Previous studies have shown that the expression of social play behaviour is modulated by endocannabinoid neurotransmission. Indirect cannabinoid agonists, i.e. drugs that prolong endocannabinoid signaling, such as URB597 (which inhibits FAAH, the enzyme that degrades the endocannabinoid anandamide) or VDM11 (which blocks endocannabinoid reuptake) enhanced social play in rats [30,59,61-63]. Interestingly, the effects of endocannabinoids on social play were found to depend on opioid receptor stimulation, and vice versa [61].

In the present study, we aimed to dissociate the role of endocannabinoids in the motivational and pleasurable properties of 
social play behaviour. To measure the motivational aspects of social play behaviour, we used an operant conditioning task that we recently developed, in which rats respond for access to a playful partner under a progressive ratio schedule of reinforcement [2]. Place conditioning was used to assess the pleasurable aspects of social play $[10,13,14,55,60]$. Since treatment with URB597 was previously found not to affect responding for food and drug rewards in rats and non-human primates [3,18,24,25,34,51], we hypothesized that enhancing anandamide levels with URB597 would increase the pleasurable aspects of social play without affecting responding for social play. Conversely, since genetic and pharmacological blockade of CB1 cannabinoid receptors decreases the motivation to respond for food $[23,41,49,76]$ and drugs of abuse [15,27], and affect food$[11,47]$ conditioned place preference, we hypothesized that treatment with the CB1 cannabinoid receptor antagonist rimonabant would decrease both the motivational and pleasurable aspects of social play.

\section{Materials and methods}

\subsection{Animals}

Male Wistar rats (Charles River, Sulzfeld, Germany) arrived in our animal facility at 21 days of age and were housed in groups of four in $40 \times 26 \times 20 \mathrm{~cm}(l \times w \times h)$ Macrolon cages under controlled conditions (ambient temperature $20-21^{\circ} \mathrm{C}, 60-65 \%$ relative humidity, and $12 / 12 \mathrm{~h}$ light cycle with lights on at 7.00 a.m.). Food and water were available ad libitum. All animals used were experimentally naïve. All experiments were approved by the Animal Ethics Committee of Utrecht University and were conducted in accordance with Dutch laws (Wet op de Dierproeven, 1996) and European regulations (Guideline 86/609/EEC).

\subsection{Drugs}

URB597 (Tocris Cookson, Avonmouth, UK) and rimonabant (National Institute of Mental Health's Chemical Synthesis and Drug Supply Program, Bethesda, MD, USA) were dissolved in 5\% Tween80/5\% polyethylene glycol/saline. URB597 and rimonabant were administered intra-peritoneally (i.p.), $2 \mathrm{~h}$ and $30 \mathrm{~min}$ before testing, respectively. Drug doses and pre-treatment intervals were based on previous studies [61-63].

\subsection{Operant conditioning paradigm}

\subsubsection{Apparatus}

Behavioural testing was conducted in an operant conditioning chamber (Med Associates, Georgia, VT, USA) divided into two equally sized compartments $(25 \times 30 \times 25 \mathrm{~cm}, l \times w \times h)$. The compartments were separated by a Plexiglas wall with 42 small holes $(\varnothing$ $0.5 \mathrm{~cm}$ ) and an automated metal door in the middle. Both compartments had a metal grid floor and a Plexiglas lid which contained a house-light $(2 \mathrm{~W})$. One compartment (the lever pressing compartment') was equipped with two $4.8 \mathrm{~cm}$-wide retractable levers, located on opposite sides of the compartment. Above each lever was a cue light $(2.5 \mathrm{~W})$. One lever was designated as the active lever and the other as the inactive lever; allocation of the left or right lever as active was counterbalanced between animals. Experimental events and data recording were controlled using Med PC software (Med Associates, Georgia, VT, USA).

\subsubsection{Experimental procedure}

Operant conditioning was performed as previously described [2]. All experiments were performed under red light conditions, since the performance of social play behaviour is inhibited by bright light conditions [68]. Animals were randomly paired with a test partner from another home cage. Animals in a test pair did not differ by more than $10 \mathrm{~g}$ in body weight at the start of the experiment. A test pair consisted of one experimental animal and its stimulus partner. At 24 days of age, test pairs were habituated to the test cage for $10 \mathrm{~min}$. After the habituation session, animals were isolated for $24 \mathrm{~h} /$ day for 5 consecutive days/week, except in the experiment in which both animals received URB597. In this experiment, animals were also isolated for $2 \mathrm{~h}$ /day prior to testing after being socially housed for at least $24 \mathrm{~h}$. Next, the animals received two shaping sessions on two consecutive days. During these shaping sessions, the cue light was presented, the lever retracted and the door opened when the experimental animal approached the active lever. Rats were allowed to interact for two minutes after which the door closed and each rat was placed back into its starting compartment by the experimenter. This procedure was repeated 7 times in each shaping session. In addition, if an animal did not perform any active lever presses during acquisition sessions, it received an additional shaping session later that day or on the next day.

On the fourth day, the lever pressing sessions (20 min) commenced under a fixed ratio (FR)-1 schedule of reinforcement. Under this FR-1 schedule of reinforcement, each active lever press resulted in presentation of the cue light, retraction of both levers, and opening of the door, after which animals were allowed to freely interact for 2 min. After acquisition of the task under the FR-1 schedule (i.e., when an animal obtained at least six out of eight possible rewards on two consecutive days), a progressive ratio (PR) schedule of reinforcement was introduced. When rats met the response requirement, the cue light was illuminated, both levers retracted and the door opened for $1 \mathrm{~min}$, during which the animals could freely interact. Animals received one session per day, for 5 consecutive days/week. During the other 2 days/week animals were socially housed with their original cage-mates. After responding had stabilized, defined as obtaining at least six rewards on three consecutive days with a variation of no more than two rewards, drug treatment started according to a Latin Square design. Inactive lever presses were recorded, but had no programmed consequences.

\subsection{Place conditioning paradigm}

\subsubsection{Apparatus}

The place conditioning setup (TSE System, Bad Homburg, Germany) comprised eight boxes, each consisting of three compartments with removable Plexiglas lids. The two conditioning compartments were equally sized $(30 \mathrm{~cm} \times 5 \mathrm{~cm} \times 30 \mathrm{~cm}$; $l \times w \times h)$ and separated by the third, neutral, compartment $(10 \mathrm{~cm} \times 25 \mathrm{~cm} \times 30 \mathrm{~cm} ; l \times w \times h)$. The two conditioning compartments had different visual and tactile cues: one had black-and-white striped walls and a floor with wide metal mesh, and the other had black walls and a floor with fine metal mesh. The compartment with black walls had a white light ( $2 \mathrm{~W})$ mounted on the Plexiglas lid, to achieve a comparable light intensity in both conditioning compartments. The middle compartment had white walls, a smooth floor, and a white light $(2 \mathrm{~W})$ on the lid. The position of the animal in the apparatus was monitored by an array of photo-beam sensors located $2.5 \mathrm{~cm}$ above the floor. The time spent in each compartment (in $\mathrm{msec}$ ) was recorded by a computer. All experiments were performed in a dimly lit room, since testing under bright light conditions reduces the performance of social play behaviour [68].

\subsubsection{Experimental procedure}

Place conditioning was performed as previously described $[1,58]$. At 26 days of age (experimental day 1 ), each rat was placed in the middle compartment of the apparatus and pre-conditioning side preference was determined by allowing the rats to move freely in the three compartments for $15 \mathrm{~min}$. On the basis of their pref- 

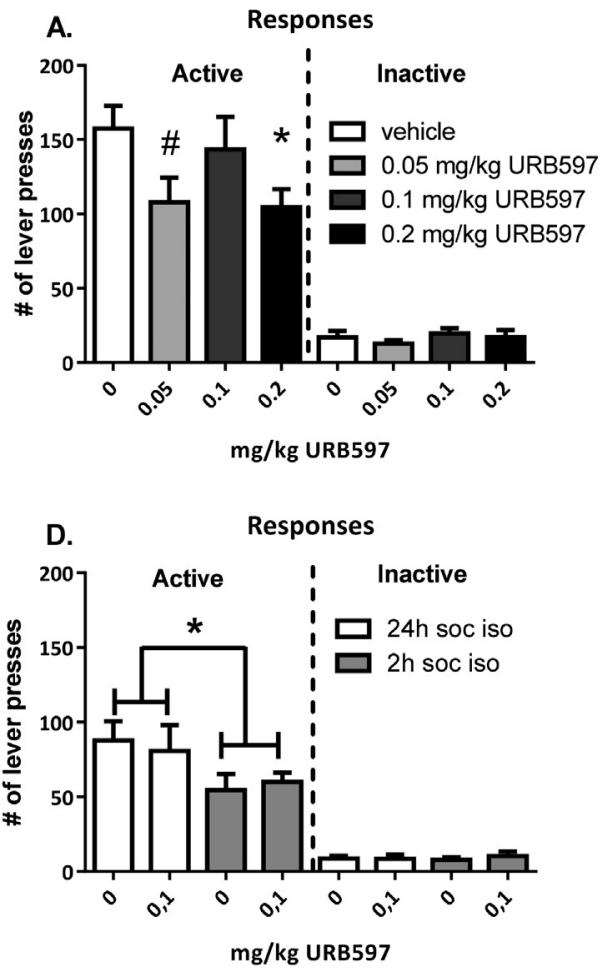
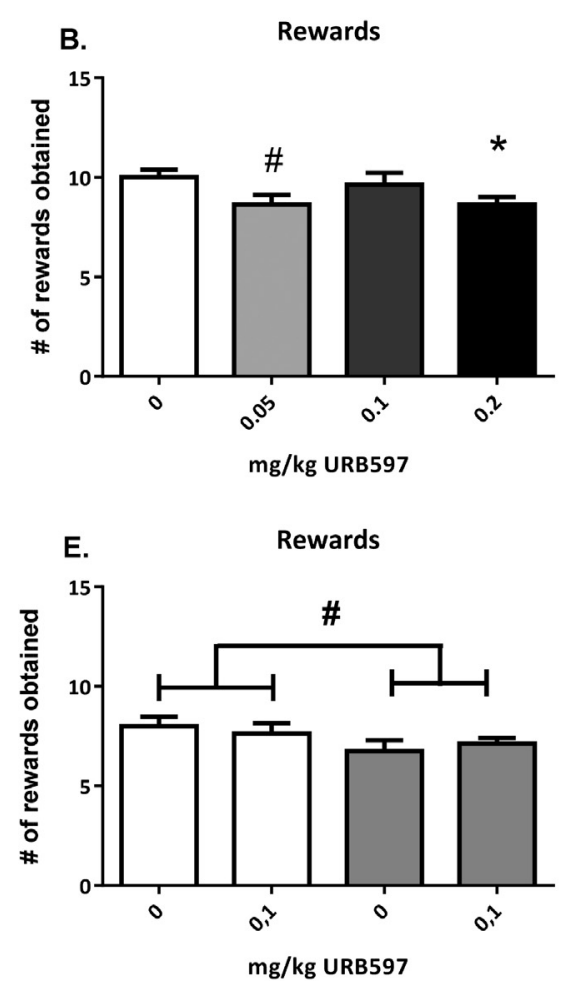

c.

Breakpoint
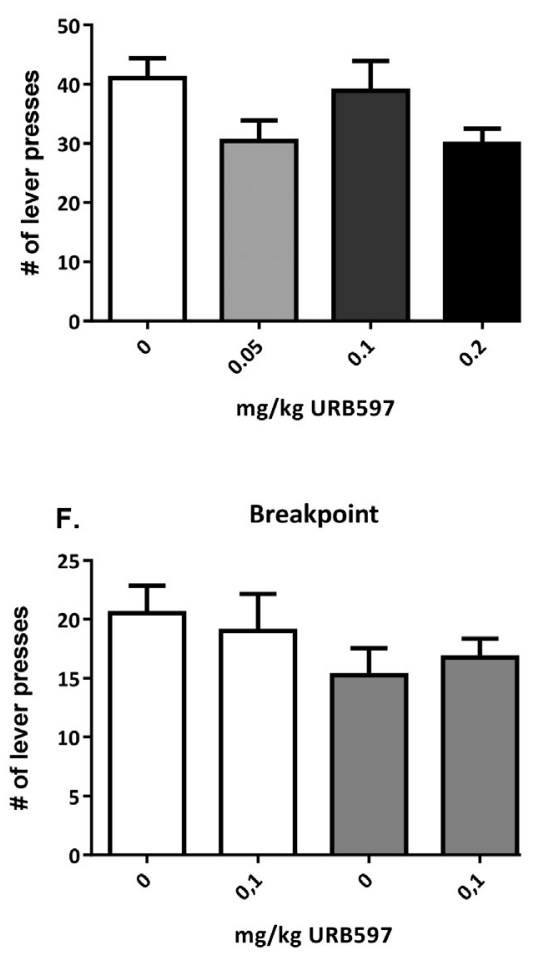

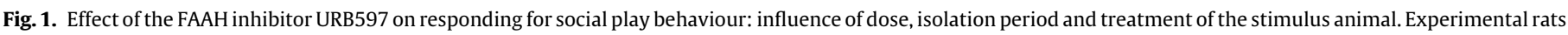

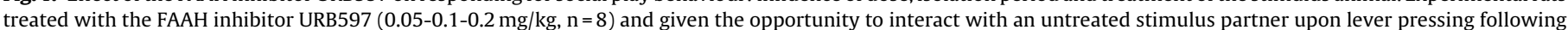

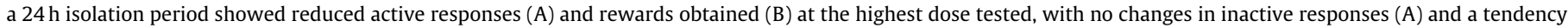

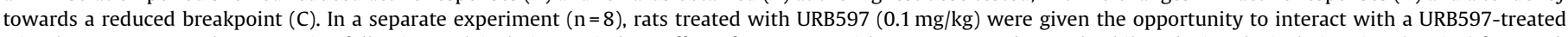

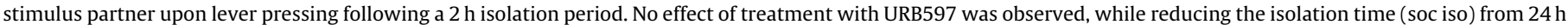

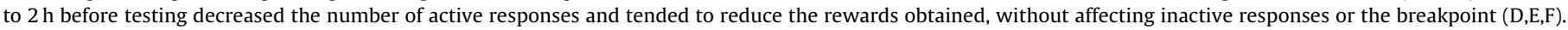
Data are represented as mean + SEM. ${ }^{\#} 0.08>\mathrm{p}>0.05$ (trend), ${ }^{*} \mathrm{p}<0.05$, relative to vehicle $(0 \mathrm{mg} / \mathrm{kg}$ URB597/24h social isolation) treatment.

erence scores, rats were assigned to a compartment in which they would be allowed social interaction during conditioning. A counterbalanced place conditioning design was used [64,71]. Thus, on the basis of their baseline preference scores (i.e., time spent in each of the two conditioning compartments), the rats were assigned to a compartment in which they would be allowed social interaction during conditioning, so that the baseline preference in each test group for the (to be) social-paired and (to be) non-social paired compartments approximated $50 \%$. Thus, based on their preconditioning performance, some of the rats were conditioned in their preferred compartment, while some were conditioned in their non-preferred compartment. After the pre-conditioning test, the rats were individually housed to increase their motivation for social interaction and to facilitate the development of social play-induced CPP $[1,33,36,60,70]$; Place conditioning began on day 2 . On days 2 , 4,6 , and 8 , the rats were placed for $30 \mathrm{~min}$ in one compartment with an initially unfamiliar partner (social session) in the morning and were placed alone in the other compartment (non-social session) in the afternoon. On day 3, 5, 7, and 9 the order of the sessions was reversed. Social and non-social sessions were separated by at least three hours. Drugs were administered 30 min (rimonabant) or $2 \mathrm{~h}$ (URB597) before the start of each social session. On day 10 , the rats were placed in the middle compartment and were allowed to explore the entire apparatus for $15 \mathrm{~min}$. The time spent in each compartment during this test was recorded to determine place preference.

\subsection{Statistical analysis}

Data were analysed using SPSS software 23.0 for Windows and expressed as mean + SEM. Data were analysed using a repeated measures ANOVA with drug dose as within-subjects factor followed by a paired Student's $t$-test when appropriate. Operant responding was analysed with lever, treatment and, where appropriate, isolation time as a within-subjects factor. The breakpoints under the PR schedule of reinforcement are derived from an escalating curve, which violates the homogeneity of variance. Therefore, breakpoints were analysed using the non-parametric Friedman test, followed by a post-hoc Wilcoxon signed ranks test when appropriate. The duration of rimonabant-induced scratching behaviour was calculated as a percentage of time.

Place conditioning data were expressed as mean time spent in the social paired and non-social paired compartment + SEM. Place conditioning data were analysed using a two-way ANOVA, with compartment and treatment as factors, followed by paired Student's $t$-test when appropriate.

\section{Results}

3.1. Effects of the FAAH inhibitor URB597 on responding for social play: influence of dose, isolation period and treatment of the stimulus animal

When experimental rats were treated with the FAAH inhibitor URB597 and had the opportunity to interact with an vehicle- 
treated stimulus partner upon lever pressing, URB597 (URB: $0.05-0.1-0.2 \mathrm{mg} / \mathrm{kg}$ ) altered operant responding for social play $\left(\mathrm{F}_{\text {treatment }}(3,21)=3.47, \mathrm{p}=0.03 ; \mathrm{F}_{\text {lever }}\right.$ treatment $(3,21)=4.42, \mathrm{p}=0.02$, $\mathrm{n}=8)$. Administration of URB597 tended to reduce responding on the active lever at the lowest dose $(t(7)$ veh $-0.05=2.26, \mathrm{p}=0.06)$ and significantly decreased it at the highest dose $\left(t(7)_{\text {veh }-0.2}=3.17\right.$, $\mathrm{p}=0.02$ ), but did not affect inactive lever presses (Fig. 1A). In addition, URB597 tended to reduce the number of rewards obtained at the lowest dose and significantly decreased it at the highest dose $\left(\mathrm{F}_{\text {treatment }}(3,21)=3.62, \mathrm{p}=0.03 ; \mathrm{t}(7)_{\text {veh }-0.05}=2.31, \mathrm{p}=0.05\right.$;

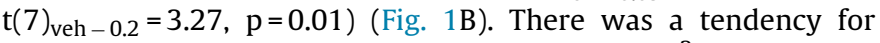
URB597 treatment to reduce the breakpoint $\left(X^{2}=7.34, d f=3\right.$, $\mathrm{p}=0.06$ ) (Fig. 1C).

URB597 was previously found to enhance social play behaviour, but only when both animals in a test pair were treated, and following a short-time isolation period before testing [63]. Therefore, we conducted an experiment in which we treated both the experimental and stimulus rats with $0.1 \mathrm{mg} / \mathrm{kg}$ URB597 or vehicle, and isolated them for $2 \mathrm{~h}$ prior to testing in the operant paradigm. In this experiment, a significant effect of the isolation period before testing was observed, with no treatment effects $\left(F_{\text {isolation }}(1,7)=5.90, p=0.05 ; F_{\text {isolation }}{ }^{*}\right.$ lever $(1,7)=6.02$, $\mathrm{p}=0.04 ; \mathrm{F}_{\text {isolation }}{ }^{*}$ treatment $\left.(1,7)=0.34, \mathrm{p}=0.58 ; \mathrm{n}=8\right)$. Animals discriminated between the levers $\left(F_{\text {lever }}(1,7)=57.73, p<0.001\right)$ but URB597 did not affect the number of lever presses $\left(F_{\text {treatment }}(1,7)=0.003, p=0.96 ; F_{\text {lever }}\right.$ treatment $(1,7)=0.08, p=0.79$; $\mathrm{F}_{\text {isolation*lever*treatment }}(1,7)=0.25, \mathrm{p}=0.63$ ) (Fig. 1D). The number of rewards tended to decrease with a shorter isolation time $\left(\mathrm{F}_{\text {isolation }}(1,7)=4.83, \mathrm{p}=0.06\right)$ (Fig. 1E) but this was unaffected by treatment $\left(F_{\text {treatment }}(1,7)=0.001, p=0.99\right.$; $\mathrm{F}_{\text {isolation }}$ treatment $\left.(1,7)=0.80, \mathrm{p}=0.40\right)$. The breakpoint was not altered as a result of isolation time or treatment $\left(X^{2}=4.39, \mathrm{df}=3\right.$, $\mathrm{p}=0.22$ ) (Fig. 1F).

\subsection{Effects of the FAAH inhibitor URB597 on social play-induced place conditioning}

URB597 did not affect the acquisition of social play-induced CPP $\left(F_{\text {treatment }}(1,62)=0.09, \mathrm{p}=0.76 ; \mathrm{F}_{\text {compartment }}{ }^{*}\right.$ treatment $(1,62)=0.001$, $\mathrm{p}=0.98$ ). The animals spent more time in the social compartment compared to the non-social compartment $\quad\left(\mathrm{F}_{\text {compartment }}(1,62)=11.00, \quad \mathrm{p}=0.002 ; \mathrm{n}(\right.$ vehicle $)=16$, $\mathrm{n}(\mathrm{URB})=17$ ) (Fig. 2A). URB597 did not induce CPP by itself $\left(\mathrm{F}_{\text {compartment }}(1,28)=0.82, \mathrm{p}=0.37 ; \mathrm{F}_{\text {treatment }}(1,28)=1.26, \mathrm{p}=0.27\right.$; $\left.\mathrm{F}_{\text {treatment }}{ }^{\text {compartment }}(1,28)=1.18, \mathrm{p}=0.29 ; \mathrm{n}=8\right)$ (Fig. 2B).

\subsection{Effects of the CB1 cannabinoid receptor antagonist rimonabant on operant responding for social play}

Treatment with the CB1 receptor antagonist rimonabant $(0.1-0.3-1.0 \mathrm{mg} / \mathrm{kg})$, reduced responding for social play ( $\left.F_{\text {treatment }}(3,21)=3.59, \quad \mathrm{p}=0.03, \mathrm{n}=8\right)$. Animals discriminated between the active and inactive lever $\left(F_{\text {lever }}(1,7)=136.81\right.$, $\left.\mathrm{p}<0.001 ; \mathrm{F}_{\text {lever*treatment }}(3,21)=2.72, \mathrm{p}=0.07\right)$. Treatment with the highest dose of rimonabant $(1 \mathrm{mg} / \mathrm{kg})$, decreased the number of active responses $\left(t(7)_{\text {veh }-1.0}=2.57, \mathrm{p}=0.04\right.$ ) (Fig. $3 \mathrm{~A}$ ). In addition, the number of rewards obtained was significantly reduced at the highest dose $\left(F_{\text {treatment }}(3,21)=4.16, \mathrm{p}=0.02 ; \mathrm{t}(7)_{\mathrm{veh}-1.0}=3.13\right.$, $\mathrm{p}=0.02$ ) (Fig. $3 \mathrm{~B}$ ), and a trend toward a reduced breakpoint was observed $\left(X^{2}=6.46, d f=3, p=0.09\right)$ (Fig. $\left.3 C\right)$. Since rimonabant is known to induce pruritic effects $[12,42,54,75]$, the time animals spent scratching was also scored. The time spent scratching during responding was significantly affected by rimonabant treatment $\left(F_{\text {treatment }}(3,21)=6.67, p=0.03\right)$ (Fig. 3D). Scratching was increased significantly by 0.3 and $1.0 \mathrm{mg} / \mathrm{kg}$ rimonabant $\left(\mathrm{t}(7)_{\mathrm{veh}-0.1}=-2.03\right.$, $\left.\mathrm{p}=0.08 ; \mathrm{t}(7)_{\text {veh }-0.3}=-2.77, \mathrm{p}=0.03 ; \mathrm{t}(7)_{\text {veh }-1.0}=-2.80, \mathrm{p}=0.03\right)$.

\subsection{Effects of rimonabant on social play-induced place conditioning}

Rimonabant treatment $(0.1-0.3 \mathrm{mg} / \mathrm{kg})$ did not affect acquisition of social play-induced CPP. Animals showed a significant preference for the play associated compartment ( $\left.\mathrm{F}_{\text {compartment }}(1,58)=43.72, \mathrm{p}<0.001\right)$ but there was no effect of treatment $\left(\mathrm{F}_{\text {dose }}(2,58)=0.15, \mathrm{p}=0.86 ; \mathrm{F}_{\text {compartment }}{ }^{*}\right.$ dose $(2,58)=2.48$, $\mathrm{p}=0.09$ ) (Fig. 4).

\section{Discussion}

We have previously identified an important role for endocannabinoids in social play behaviour. Social play increases levels of the endocannabinoid anandamide in brain areas involved in reward and motivation [59] and treatment with drugs that increase endocannabinoid signaling by blocking endocannabinoid deactivation enhances social play [30,59,61-63]. Conversely, systemic and intracranial blockade of CB1 cannabinoid receptors decreases social play $[59,62]$.

The aim of this study was to investigate whether endocannabinoids differentially affect the motivational and pleasurable aspects of social play behaviour. We hypothesized that enhancing anandamide levels with URB597 would increase the pleasurable aspects of social play without affecting responding for social play $[3,18,24,25,34,51]$, whereas treatment with the CB1 cannabinoid receptor antagonist rimonabant would decrease both the motivational $[15,23,27,41,49,76]$ and pleasurable aspects $[11,31,47]$ of social play.

To test this hypothesis, we investigated the consequences of pharmacological enhancement or reduction of endocannabinoid activity in two setups designed to assess the motivational or pleasurable properties of social play, i.e., responding for social play under a progressive ratio schedule of reinforcement [2] and social play-induced conditioned place preference [60]), respectively.

\subsection{Effects of URB597 and rimonabant on responding for social play behaviour}

At a dose known to increase the expression of social play behaviour (i.e. $0.1 \mathrm{mg} / \mathrm{kg}$; [30], treatment with URB597 did not affect responding for social play, neither in animals isolated for $24 \mathrm{~h}$ nor for $2 \mathrm{~h}$ before testing. URB597 modestly reduced responding for social play at a higher dose $(0.2 \mathrm{mg} / \mathrm{kg})$ in animals isolated for $24 \mathrm{~h}$ prior to testing. These findings are in line with previous studies showing that treatment with URB597 does not affect responding for food [3,25,34], nicotine [18], heroin [51], anandamide, THC and cocaine $[3,24]$ in rats and non-human primates. Similarly, inhibiting the reuptake of anandamide with AM404 had no effect on responding for food in rats [21]. Together, these data show that increasing anandamide tone through inhibition of its degradation or reuptake does not profoundly alter the incentive motivational properties of rewards.

Blocking CB1 cannabinoid receptors with rimonabant reduced operant responding for social play. In previous studies, treatment with rimonabant was found to reduce operant responding for food [16,32,49,77], chocolate-drinks [28] but not intracranial selfstimulation [4]. Rimonabant treatment also reduced the intake of food [72-74] chocolate-drink, and ethanol [5], suggesting that a decrease in the pleasurable properties of rewards contributes to the reduction in operant responding induced by rimonabant. However, the reduction in operant responding induced by rimonabant may also be secondary to frequent episodes of scratching induced 

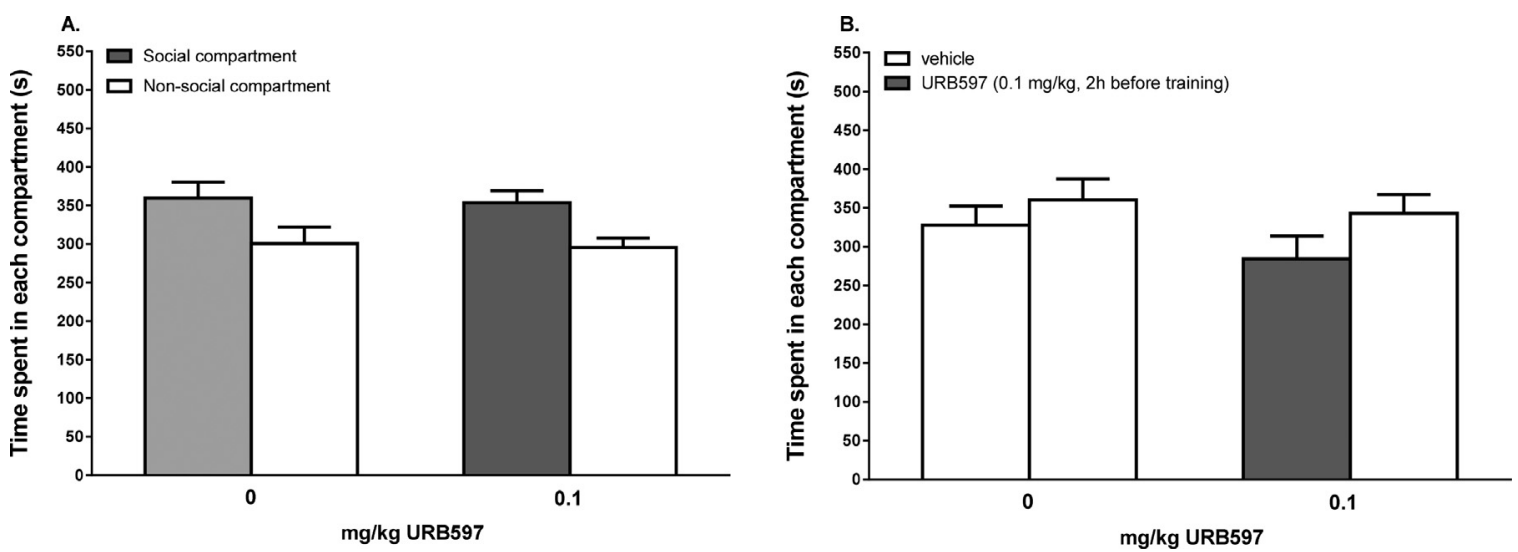

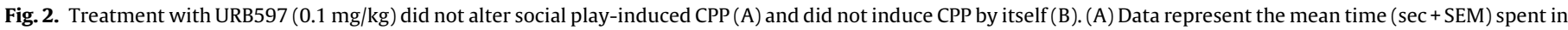

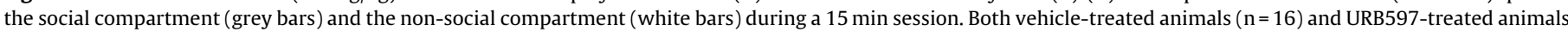

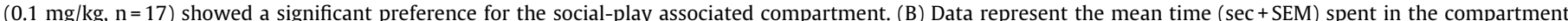

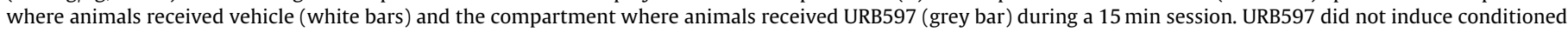
place preference or aversion.

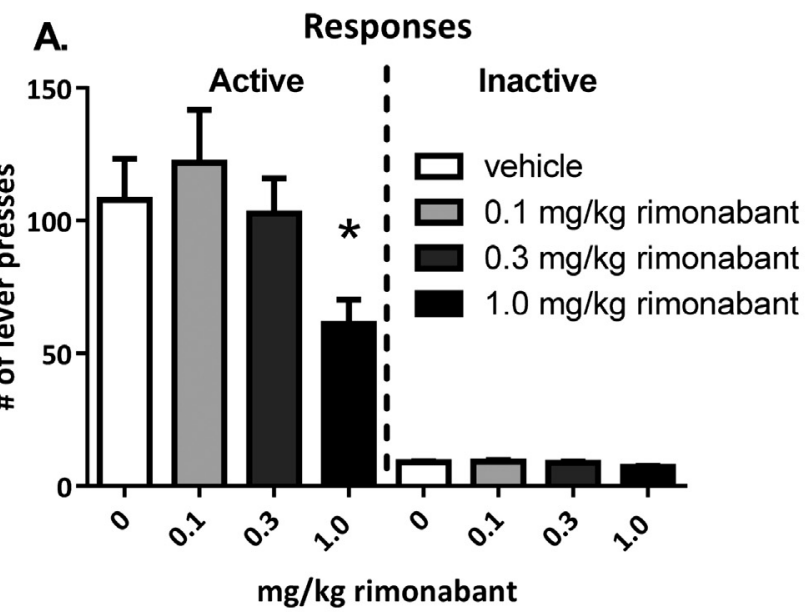

C.

Breakpoint

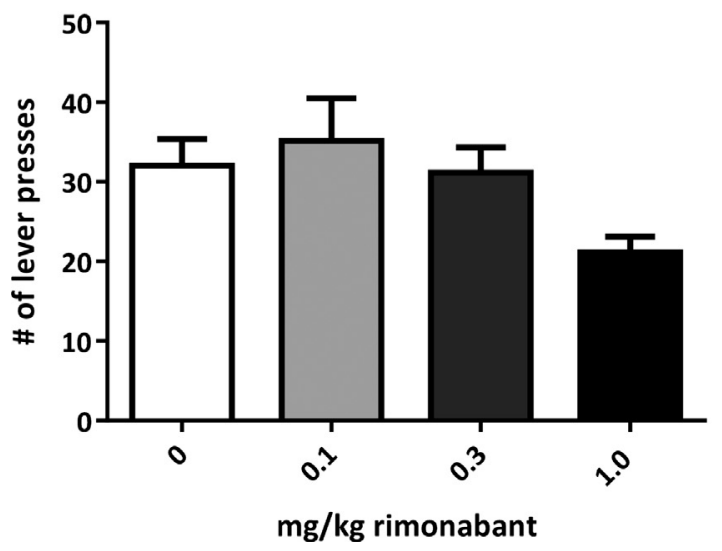

B.

Rewards

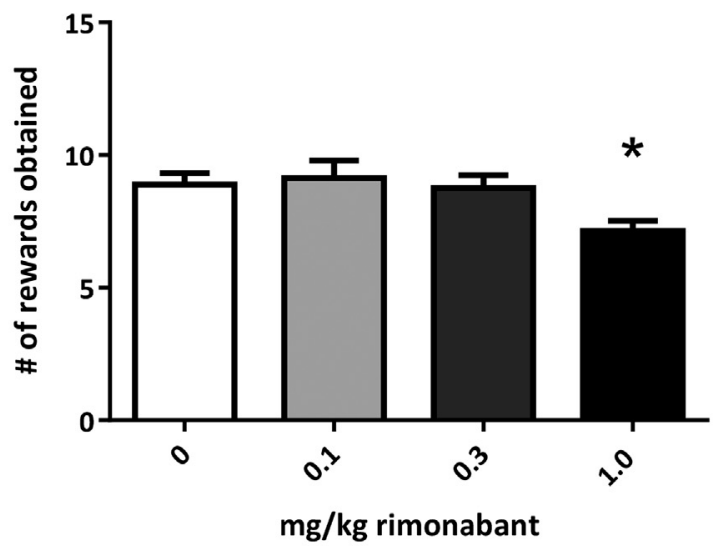

D. Scratching during responding

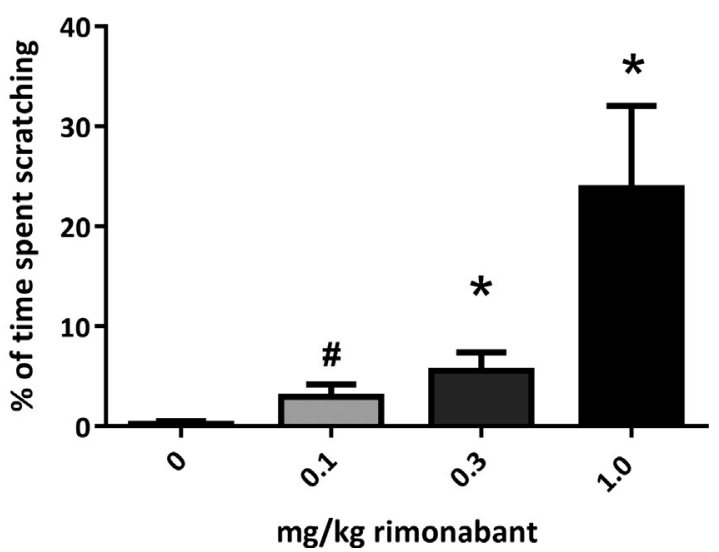

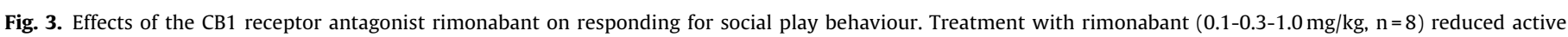

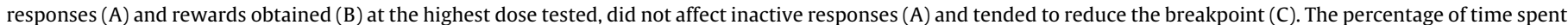

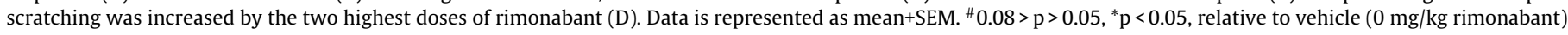
treatment.

by the drug $[12,42,54,75]$. Indeed, during lever pressing for social play, the animals treated with the highest dose of rimonabant $(1.0 \mathrm{mg} / \mathrm{kg})$ spent about $25 \%$ of their time scratching, which likely interfered with operant responding. Thus, the reduction in oper- ant responding could also be the result of behavioural competition, which has been proposed to underlie certain other behavioural effects of rimonabant as well (e.g. Ref. [54]). In sum, decreases in responding for rewards, including social play behaviour, after 


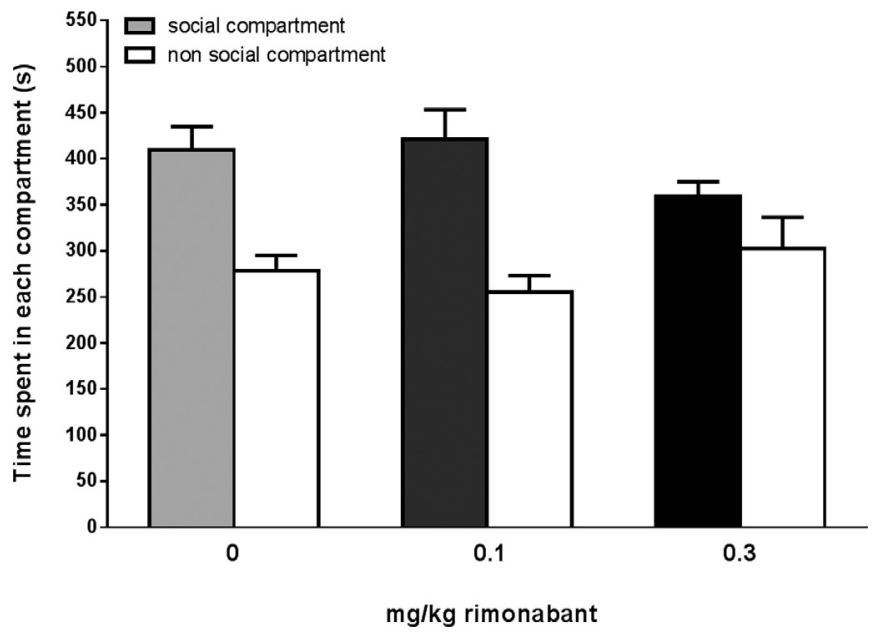

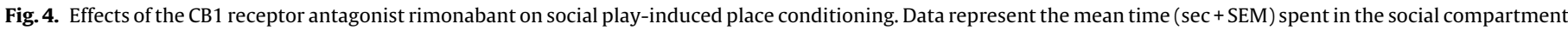

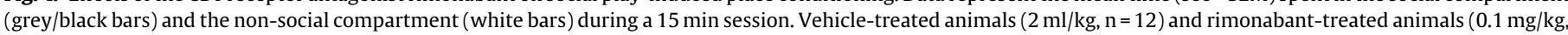
$\mathrm{n}=12,0.3 \mathrm{mg} / \mathrm{kg}, \mathrm{n}=12$ ) showed a significant preference for the social-play associated compartment.

treatment with rimonabant may result from effects on incentive motivation, pleasure, behavioural competition, or a combination of these. Future studies with intracranial administration may clarify the consequences of central blockade of CB1-receptors on operant responding for rewards without the interference of competing stereotypic behaviours.

In contrast to the lack of consistent effects on incentive motivation by indirectly enhancing endocannabinoid levels, targeting CB1-receptors with direct agonists has been found to affect the motivational aspects of both food and drug rewards (for reviews see Refs. [37,38]). The discrepancies between effects of direct vs indirect cannabinoid agonists illustrate the peculiar dynamics of endocannabinoid signaling, whereby these neuromodulators are released 'on demand' after changes in synaptic activity [20]. Thus, endocannabinoid degradation inhibitors or reuptake blockers only increase ongoing endocannabinoid signaling, whereas direct receptor agonists will increase cannabinoid activity throughout the central nervous system. As a result, administration of direct and indirect cannabinoid agonists can evoke differential effects on behaviour (e.g. Ref. [61]). With regard to operant responding for rewards, we think that there is modest, if any, endocannabinoid activity in brain regions that support incentive motivational processes, so that interfering with endocannabinoid degradation will hardly affect this behaviour. In contrast, stimulating cannabinoid neurotransmission in other brain regions may evoke mental states that do result in changes in responding for rewards.

\subsection{Effects of URB597 and rimonabant on social play-induced place conditioning}

Enhancing endocannabinoid levels by URB597 treatment during place conditioning did not alter the expression of social playinduced CPP, although at this dose, URB597 has been found to enhance social play behaviour [30]. A likely explanation for the lack of effect social play behaviour-induced CPP is that in the place conditioning paradigm, the animals are isolated for $24 \mathrm{~h}$, which leads to near-maximal levels of social play behaviour [33,70]. Possibly, this is associated with maximal levels of endocannabinoid signaling, so that treatment with URB597 can not influence this behaviour further. Consistent with previous work [22,44], URB597 did not induce CPP by itself, although URB597 has been found to prevent the development of nicotine-induced CPP in adult rats $[45,46]$.

Blocking CB1 receptors with rimonabant did not significantly affect the acquisition of social play-induced CPP. However, visual inspection of Fig. 4 shows that the social play-induced CPP was somewhat reduced after treatment with $0.3 \mathrm{mg} / \mathrm{kg}$ rimonabant. Indeed, Ref. [62] showed that rimonabant, at doses of $0.3 \mathrm{mg} / \mathrm{kg}$ and higher reduced social play behaviour. Thus, rimonabant may have a modest effect on the pleasurable properties of social play, although we cannot exclude that the pruritic effects of rimonabant interfered with behaviour in this case as well. Previous studies have shown that food- and drug-induced CPP was inhibited after CB1 receptor blockade $[11,47]$. The present data indicate that CB1 receptor antagonist treatment only modestly affected the pleasurable properties of social play behaviour.

Contrary to our hypothesis, enhancing endocannabinoid tone as well as blocking CB1 receptors did not lead to robust changes in the pleasurable aspects of social play behaviour as measured in our place conditioning set-up. This indicates that endocannabinoids have no primary role in the pleasurable properties of social play behaviour, but future studies with suboptimal conditioning paradigms and/or central administration of cannabinoid drugs may shed light on the role of endocannabinoid signaling in social play reward.

\section{Conclusion}

These data provide new insights into the role of endocannabinoids in the motivational and pleasurable aspects of social play behaviour. Endocannabinoids modulate the expression of social play behaviour [59]. The present results extend these findings by showing that they do not differentially affect the motivational and pleasurable properties of social play. Thus, rather than by specifically interfering with one of its emotional components, endocannabinoid signaling may modulate the expression of social play behaviour by altering the coherence of its behavioural components or prolonging the playful interaction.

\section{Funding}

Supported by National Institute on Drug Abuse GrantR01DA022628 (LJMJV), Netherlands Organization for Scientific Research (NWO) Veni grant91611052 (VT) and Marie Curie Career Reintegration Grant PCIG09-GA-2011-293589 (VT). The funding organizations had no further role in study design, in the collection, analysis and interpretation of data, in the writing of the report and in the decision to submit the paper for publication. 


\section{Appendix A. Supplementary data}

Supplementary data associated with this article can be found, in the online version, at http://dx.doi.org/10.1016/j.phrs.2016.04. 031.

\section{References}

[1] E.J.M. Achterberg, V. Trezza, L.J.M.J. Vanderschuren, Beta-adrenoreceptor stimulation mediates reconsolidation of social reward-related memories, PLoS One 7 (2012) e39639.

[2] E.J.M. Achterberg, L.W.M. van Kerkhof, M. Servadio, M.M. van Swieten, D.J. Houwing, M. Aalderink, N.V. Driel, V. Trezza, L.J.M.J. Vanderschuren, Contrasting roles of dopamine and noradrenaline in the motivational properties of social play behaviour in rats, Neuropsychopharmacology 41 (2016) 858-868

[3] P. Adamczyk, A.C. McCreary, E. Przegalinski, P. Mierzejewski, P. Bienkowski, M. Filip, The effects of fatty acid amide hydrolase inhibitors on maintenance of cocaine and food self-administration and on reinstatement of cocaine-seeking and food-taking behaviour in rats, J. Physiol. Pharmacol. 60 (2009) 119-125.

[4] J.C. Arnold, G.E. Hunt, I.S. McGregor, Effects of the cannabinoid receptor agonist CP 55,940 and the cannabinoid receptor antagonist SR. 141716 on intracranial self-stimulation in Lewis rats, Life Sci. 70 (2009) 97-108.

[5] M. Arnone, J. Maruani, F. Chaperon, M.H. Thiébot, M. Poncelet, P. Soubrié, G. Le Fur, 1997), Selective inhibition of sucrose and ethanol intake by SR an antagonist of central cannabinoid (CB1) receptors, Psychopharmacology (Berl) 132 (1997) 104-106.

[6] P.J.J. Baarendse, D.S. Counotte, P. O’Donnell, L.J.M.J. Vanderschuren, Social experience during adolescence is critical for the development of cognitive control and dopamine modulation of prefrontal cortex function, Neuropsychopharmacology 38 (2013) 1485-1494.

[7] M.F. Barbano, M. Cador, Opioids for hedonic experience and dopamine to get ready for it, Psychopharmacology (Berl) 191 (2007) 497-506.

[8] M.F. Barbano, M. Le Saux, M. Cador, Involvement of dopamine and opioids in the motivation to eat: influence of palatability, homeostatic state, and behavioural paradigms, Psychopharmacology (Berl) 203 (2009) 475-487.

[9] K.C. Berridge, T.E. Robinson, J.W. Aldridge, Dissecting components of reward: 'liking', 'wanting', and learning, Curr. Opin. Pharmacol. 9 (2009) 65-73.

[10] D.J. Calcagnetti, M.D. Schechter, Place conditioning reveals the rewarding aspect of social interaction in juvenile rats, Physiol. Behav. 51 (1992) 667-672.

[11] F. Chaperon, P. Soubrié, A.J. Puech, M.-H. Thiébot, Involvement of central cannabinoid (CB1) receptors in the establishment of place conditioning in rats, Psychopharmacology (Berl) 135 (1998) 324-332.

[12] S.A. Cook, J.A. Lowe, B.R. Martin, CB1 receptor antagonist precipitates withdrawal in mice exposed to Delta9-tetrahydrocannabinol, J. Pharmacol. Exp. Ther. 285 (1998) 1150-1156.

[13] W.F. Crowder, C.W. Hutto Jr., Operant place conditioning measures examined using two nondrug reinforcers, Pharmacol. Biochem. Behav. 41 (1992) 817-824.

[14] L.A. Douglas, E.I. Varlinskaya, L.P. Spear, Rewarding properties of social interactions in adolescent and adult male and female rats: impact of social versus isolate housing of subjects and partners, Dev. Psychobiol. 45 (2004) 153-162.

[15] D. Economidou, L. Mattioli, C. Cifani, M. Perfumi, M. Massi, V. Cuomo, L. Trabace, R. Ciccocioppo, Effect of the cannabinoid CB1 receptor antagonist SR-141716A on ethanol self-administration and ethanol-seeking behaviour in rats, Psychopharmacology (Berl) 183 (2006) 394-403.

[16] J. Evenden, T. Ko, The effects of anorexic drugs on free-fed rats responding under a second-order FI15-min (FR10:S) schedule for high incentive foods, Behav. Pharmacol. 18 (2007) 61-69.

[17] L. Fattore, P. Fadda, W. Fratta, Endocannabinoid regulation of relapse mechanisms, Pharmacol. Res. 56 (2007) 418-427.

[18] B. Forget, K.M. Coen, B. Le Foll, Inhibition of fatty acid amide hydrolase reduces reinstatement of nicotine seeking but not break point for nicotine self-administration? comparison with $\mathrm{CB}(1)$ receptor blockade, Psychopharmacology (Berl) 205 (2009) 613-624.

[19] C.M. Friemel, A. Zimmer, M. Schneider, The CB1 receptor as an important mediator of hedonic reward processing, Neuropsychopharmacology 39 (2014) 2387-2396.

[20] T.F. Freund, I. Katona, D. Piomelli, Role of endogenous cannabinoids in synaptic signaling, Physiol. Rev. 83 (2003) 1017-1066.

[21] I. Gamaleddin, M. Guranda, M. Scherma, W. Fratta, A. Makriyannis, S.K. Vadivel, S.R. Goldberg, B. Le Foll, AM404 attenuates reinstatement of nicotine seeking induced by nicotine-associated cues and nicotine priming but does not affect nicotine- and food-taking, J. Psychopharmacol. 27 (2013) 564-571.

[22] G. Gobbi, F.R. Bambico, R. Mangieri, M. Bortolato, P. Campolongo, M. Solinas, T. Cassano, M.G. Morgese, G. Debonnel, A. Duranti, A. Tontini, G. Tarzia, M. Mor, V. Trezza, S.R. Goldberg, V. Cuomo, D. Piomelli, Antidepressant-like activity and modulation of brain monoaminergic transmission by blockade of anandamide hydrolysis, Proc. Natl. Acad. Sci. U.S.A. 102 (2005) 18620-18625.

[23] G. Hernandez, J.F. Cheer, Effect of CB1 receptor blockade on food-reinforced responding and associated nucleus accumbens neuronal activity in rats, J. Neurosci. 32 (2012) 11467-11477.
[24] Z. Justinova, R.A. Mangieri, M. Bortolato, S.I. Chefer, A.G. Mukhin, J.R. Clapper, A.R. King, G.H. Redhi, S. Yasar, D. Piomelli, S.R. Goldberg, Fatty acid amide hydrolase inhibition heightens anandamide signaling without producing reinforcing effects in primates, Biol. Psychiatry 64 (2008) 930-937.

[25] B.D. Kangas, M.Z. Leonard, V.G. Shukla, S.O. Alapafuja, S.P. Nikas, A Makriyannis, J. Bergman, Comparisons of $\Delta$ 9-tetrahydrocannabinol and anandamide on a battery of cognition-related behaviour in nonhuman primates, J. Pharmacol. Exp. Ther. 357 (2016) 125-133.

[26] A.E. Kelley, Ventral striatal control of appetitive motivation: role in ingestive behaviour and reward-related learning, Neurosci. Biobehav. Rev. 27 (2004) 765-776.

[27] P. Maccioni, G. Colombo, M.A. Carai, Blockade of the cannabinoid CB1 receptor and alcohol dependence: preclinical evidence and preliminary clinical data, CNS Neurol. Disord. Drug Targets 9 (2010) 55-59.

[28] P. Maccioni, D. Pes, M.A.M. Carai, G.L. Gessa, G. Colombo, Suppression by the cannabinoid CB1 receptor antagonist, rimonabant, of the reinforcing and motivational properties of a chocolate-flavoured beverage in rats, Behav. Pharmacol. 19 (2008) 197-209.

[29] S.V. Mahler, K.S. Smith, K.C. Berridge, Endocannabinoid hedonic hotspot for sensory pleasure: anandamide in nucleus accumbens shell enhances 'liking' of a sweet reward, Neuropsychopharmacology 32 (2007) 2267-2278.

[30] A. Manduca, M. Servadio, P. Campolongo, M. Palmery, L. Trabace, L.J.M.J. Vanderschuren, V. Cuomo, V. Trezza, Strain- and context-dependent effects of the anandamide hydrolysis inhibitor URB597 on social behaviour in rats, Eur. Neuropsychopharmacol. 24 (2014) 1337-1348.

[31] M. Méndez-Díaz, P.E. Rueda-Orozco, A.E. Ruiz-Contreras, O. Prospéro-García, The endocannabinoid system modulates the valence of the emotion associated to food ingestion, Addict. Biol. 17 (2012) 725-735.

[32] F.J. Meye, V. Trezza, L.J.M.J. Vanderschuren, L.J.M.J. Ramakers, R.A.H. Adan, Neutral antagonism at the cannabinoid 1 receptor: a safer treatment for obesity, Mol. Psychiatry 18 (2013) 1294-1301.

[33] R.J.M. Niesink, J.M. Van Ree, Involvement of opioid and dopaminergic systems in isolation-induced pinning and social grooming of young rats, Neuropharmacology 28 (1989) 411-418.

[34] E. Oleson, M.V. Beckert, J.T. Morra, C.S. Lansink, R. Cachope, R.A. Abdullah, A.L. Loriaux, D. Schetters, T. Pattij, M.F. Roitman, A.H. Lichtman, J.F. Cheer, Endocannabinoids shape accumbal encoding of cue-motivated behaviour via CB1 receptor activation in the ventral tegmentum, Neuron 73 (2012) 360-373.

[35] J. Panksepp, S.M. Siviy, L. Normansell, The psychobiology of play: theoretical and methodological perspectives, Neurosci. Biobehav. Rev. 8 (1984) 465-492.

[36] J. Panksepp, W.W. Beatty, Social deprivation and play in rats, Behav. Neural Biol. 30 (1980) 197-206.

[37] L.V. Panlilio, Z. Justinova, S.R. Goldberg, Inhibition of FAAH and activation of PPAR: new approaches to the treatment of cognitive dysfunction and drug addiction, Pharmacol. Ther. 138 (2013) 84-102.

[38] L.H. Parsons, Y.L. Hurd, Endocannabinoid signalling in reward and addiction, Nat. Rev. Neurosci. 16 (2015) 579-594.

[39] S.M. Pellis, V.C. Pellis, The Playful Brain, OneWorld Publications, Oxford, 2009

[40] M. Potegal, D. Einon, Aggressive behaviours in adult rats deprived of playfighting experience as juveniles, Dev. Psychobiol. 22 (1989) 159-172.

[41] E.B. Rasmussen, S.L. Huskinson, Effects of rimonabant on behavior maintained by progressive ratio schedules of sucrose reinforcement in obese Zucker (fa/fa) rats, Behav. Pharmacol. 19 (2008) 735-742.

[42] T. Rubino, D. Vigano, E. Zagato, M. Sala, D. Parolaro, In vivo characterization of the specific cannabinoid receptor antagonist, SR. 141716A: behavioural and cellular responses after acute and chronic treatments, Synapse 35 (2000) $8-14$.

[43] J.D. Salamone, M. Correa, The mysterious motivational functions of mesolimbic dopamine, Neuron 76 (2012) 470-485.

[44] M. Scherma, J. Medalie, W. Fratta, S.K. Vadivel, A. Makriyannis, D. Piomelli, E. Mikics, J. Haller, S. Yasar, G. Tanda, S.R. Goldberg, The endogenous cannabinoid anandamide has effects on motivation and anxiety that are revealed by fatty acid amide hydrolase (FAAH) inhibition, Neuropharmacology 54 (2008) 129-140.

[45] M. Scherma, L.V. Panlilio, P. Fadda, L. Fattore, I. Gamaleddin, B. Le Foll, Z. Justinová, E. Mikics, J. Haller, J. Medalie, J. Stroik, C. Barnes, S. Yasar, G. Tanda, D. Piomelli, W. Fratta, S.R. Goldberg, Inhibition of anandamide hydrolysis by cyclohexyl carbamic acid 3'-carbamoyl-3-yl ester (URB597) reverses abuse-related behavioural and neurochemical effects of nicotine in rats, J. Pharmacol. Exp. Ther. 327 (2008) 482-490.

[46] M. Scherma, J. Medalie, W. Fratta, S.K. Vadivel, A. Makriyannis, D. Piomelli, E. Mikics, J. Haller, S. Yasar, G. Tanda, S.R. Goldberg, The endogenous cannabinoid anandamide has effects on motivation and anxiety that are revealed by fatty acid amide hydrolase (FAAH) inhibition, Neuropharmacology 54 (2008) 129-140.

[47] M.E. Singh, A.N.A. Verty, I.S. McGregor, P.E.A. Mallet, cannabinoid receptor antagonist attenuates conditioned place preference but not behavioural sensitization to morphine, Brain Res. 1026 (2004) 244-253.

[48] S.M. Siviy, J. Panksepp, In search of the neurobiological substrates for social playfulness in mammalian brains, Neurosci. Biobehav. Rev. 35 (2011) 1821-1830.

[49] M. Solinas, S.R. Goldberg, Motivational effects of cannabinoids and opioids on food reinforcement depend on simultaneous activation of cannabinoid and opioid systems, Neuropsychopharmacology 30 (2005) 2035-2045.

[50] M. Solinas, S.R. Goldberg, D. Piomelli, The endocannabinoid system in brain reward processes, Br. J. Pharmacol. 154 (2008) 369-383. 
[51] M. Solinas, L.V. Panlilio, G. Tanda, A. Makriyannis, S.A. Matthews, S.R Goldberg, Cannabinoid agonists but not inhibitors of endogenous cannabinoid transport or metabolism enhance the reinforcing efficacy of heroin in rats, Neuropsychopharmacology 30 (2005) 2046-2057.

[52] L.P. Spear, The adolescent brain and age-related behavioural manifestations, Neurosci. Biobehav. Rev. 24 (2000) 417-463.

[53] M. Špinka, R.C. Newberry, M. Bekoff, Mammalian play: training for the unexpected, Q. Rev. Biol. 76 (2001) 141-168.

[54] A.J. Tallett, J.E. Blundell, R.J. Rodgers, Grooming, scratching and feeding: role of response competition in acute anorectic response to rimonabant in male rats, Psychopharmacol 195 (2007) 27-39.

[55] K.J. Thiel, A.C. Okun, J.L. Neisewander, Social reward-conditioned place preference: a model revealing an interaction between cocaine and social context rewards in rats, Drug Alcohol Depend. 96 (2008) 202-212.

[56] V. Trezza, P.J.J. Baarendse, L.J.M.J. Vanderschuren, The pleasures of play: pharmacological insights into social reward mechanisms, Trends Pharmacol. Sci. 31 (2010) 463-469.

[57] V. Trezza, P. Campolongo, L.J.M.J. Vanderschuren, Evaluating the rewarding nature of social interactions in laboratory animals, Dev. Cogn. Neurosci. 1 (2011) 444-458.

[58] V. Trezza, R. Damsteegt, E.J.M. Achterberg, L.J.M.J. Vanderschuren, Nucleus accumbens mu-opioid receptors mediate social reward, J. Neurosci. 31 (2011) 6362-6370.

[59] V. Trezza, R. Damsteegt, A. Manduca, S. Petrosino, L.W.M. Van Kerkhof, R.J. Pasterkamp, Y. Zhou, P. Campolongo, V. Cuomo, V. Di Marzo, L.J.M.J. Vanderschuren, Endocannabinoids in amygdala and nucleus accumbens mediate social play reward in adolescent rats, J. Neurosci. 32 (2012) 14899-14908.

[60] V. Trezza, R. Damsteegt, L.J.M.J. Vanderschuren, Conditioned place preference induced by social play behaviour: parametrics, extinction, reinstatement and disruption by methylphenidate, Eur. Neuropsychopharmacol. 19 (2009) 659-669.

[61] V. Trezza, L.J.M.J. Vanderschuren, Bidirectional cannabinoid modulation of social behaviour in adolescent rats, Psychopharmacology (Berl) 197 (2008) 217-227.

[62] V. Trezza, L.J.M.J. Vanderschuren, Divergent effects of anandamide transporter inhibitors with different target selectivity on social play behaviour in adolescent rats, J. Pharmacol. Exp. Ther. 328 (2009) 343-350.

[63] V. Trezza, L.J.M.J. Vanderschuren, Cannabinoid and opioid modulation of social play behaviour in adolescent rats: differential behavioural mechanisms, Eur. Neuropsychopharmacol. 18 (2008) 519-530.

[64] T.M. Tzschentke, Measuring reward with the conditioned place preference (CPP) paradigm: update of the last decade, Addict. Biol. 12 (2007) 227-462.
[65] C.L. Van den Berg, T. Hol, J.M. Van Ree, B.M. Spruijt, H. Everts, J.M. Koolhaas, Play is indispensable for an adequate development of coping with social challenges in the rat, Dev. Psychobiol. 34 (1999) 129-138.

[66] L.J.M.J. Vanderschuren, V. Trezza, What the laboratory rat has taught us about social play behaviour: role in behavioural development and neural mechanisms, Curr. Topics Behav. Neurosci. 16 (2014) 189-212.

[67] L.J.M.J. Vanderschuren, How the brain makes play fun, Am. J. Play 2 (2010) 315-337.

[68] L.J.M.J. Vanderschuren, R.J.M. Niesink, B.M. Spruijt, J.M. Van Ree, Influence of environmental factors on social play behavior of juvenile rats, Physiol. Behav. 58 (1995) 119-123.

[69] L.J.M.J. Vanderschuren, R.J.M. Niesink, J.M. Van Ree, The neurobiology of social play behaviour in rats, Neurosci. Biobehav. Rev. 21 (1997) 309-326.

[70] L.J.M.J. Vanderschuren, V. Trezza, S. Griffioen-Roose, O.J.G. Schiepers, N. Van Leeuwen, T.J. De Vries, A.N.M. Schoffelmeer, Methylphenidate disrupts social play behaviour in adolescent rats, Neuropsychopharmacology 33 (2008) 2946-2956.

[71] M.M.J. Veeneman, H. Boleij, M.H. Broekhoven, E.M.S. Snoeren, M.M. Guitart, J. Cousijn, W. Spooren, L.J.M.J. Vanderschuren, Dissociable roles of mGlu5 and dopamine receptors in the rewarding and sensitizing properties of morphine and cocaine, Psychopharmacology (Berl) 214 (2011) 863-876.

[72] A.N.A. Verty, I.S. McGregor, P.E. Mallet, Consumption of high carbohydrate, high fat, and normal chow is equally suppressed by a cannabinoid receptor antagonist in non-deprived rats, Neurosci. Lett. 354 (2004) 217-220.

[73] A.N.A. Verty, J.R. McFarlane, I.S. McGregor, P.E. Mallet, Evidence for an interaction between CB1 cannabinoid and melanocortin MCR-4 receptors in regulating food intake, Endocrinology 145 (2004) 3224-3231.

[74] A.N.A. Verty, J.R. McFarlane, I.S. McGregor, P.E. Mallet, Evidence for an interaction between CB1 cannabinoid and oxytocin receptors in food and water intake, Neuropharmacology 47 (2004) 593-603.

[75] S.P. Vickers, L.J. Webster, A. Wyatt, C.T. Dourish, G.A. Kennett, Preferential effects of the cannabinoid CB1 receptor antagonist, SR 141716, on food intake and body weight gain of obese (fa/fa) compared to lean Zucker rats, Psychopharmacology (Berl) 167 (2003) 103-111.

[76] S.J. Ward, L.A. Dykstra, The role of CB1 receptors in sweet versus fat reinforcement: effect of CB1 receptor deletion, CB1 receptor antagonism (SR 14176A and CB1 receptor agonism (CP-55940), Behav. Pharmacol. 16 (2005) $381-388$.

[77] S.J. Ward, T.W. Lefever, C. Jackson, R.J. Tallarida, E.A. Walker, Effects of a cannabinoid1 receptor antagonist and serotonin 2c receptor agonist alone and in combination on motivation for palatable food: a dose-addition analysis study in mice, J. Pharmacol. Exp. Ther. 325 (2008) 567-576. 